\title{
MYC and BCL2 overexpression is associated with a higher class of Memorial Sloan- Kettering Cancer Center prognostic model and poor clinical outcome in primary diffuse large B-cell lymphoma of the central nervous system
}

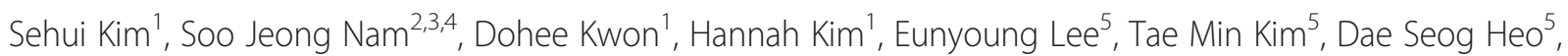
Sung Hye Park', Chul Woo Kim ${ }^{1,2,3}$ and Yoon Kyung Jeon ${ }^{1,2,3^{*}}$ (D)

\begin{abstract}
Background: Primary diffuse large B-cell lymphoma of the central nervous system (PCNS-DLBCL) is a distinct clinicopathological entity with a poor prognosis. Concurrent MYC and BCL2 overexpression predicts inferior prognosis in systemic DLBCLs. However, the prognostic significance of MYC and BCL2 in PCNS-DLBCL remains elusive.

Methods: Immunohistochemistry (IHC) of MYC, BCL2 and BCL6 was performed on tumor samples from 114 patients with PCNS-DLBCL. IHC score was assigned based on the proportion of immunostained cells.

Results: MYC, BCL2, and BCL6 IHC scores were 18.16 $\pm 19.58,58.86 \pm 35.07$, and $39.39 \pm 37.66 \%$ (mean \pm SD), respectively. Twenty-one cases (18.1\%) were designated as MYC-positive with a cutoff score of 40. BCL2 positivity was found in 87 cases (75.0 \%) using a cutoff score of 30. MSKCC (Memorial Sloan-Kettering Cancer Center prognostic model) class 2 and 3 had higher rates of MYC and/or BCL2 positivity (MYC, $P=0.012 ; B C L 2, P=0.008$; dual-positive, $P=0.022$ ). Poor KPS (Karnofsky Performance Status score $<70$ ), multifocal disease, Nottingham-Barcelona score $\geq 2$, and MSKCC class 2 and 3 were related to shorter progression-free survival (PFS) $(P=0.001,0.037,0.001$, and 0.008 , respectively). Patients with older age ( $>60$ years) showed poorer overall survival (OS) $(P=0.020)$. MYC positivity was associated with poor PFS $(P=0.027)$, while patients with BCL2 positivity exhibited a shorter OS $(P=0.010)$. Concomitant MYC and BCL2 positivity was related to poor PFS $(P=0.041)$, while the lack of both MYC and BCL2 expression was related to prolonged OS $(P=0.014)$. MYC and BCL2 expression had no independent prognostic implication by multivariate analysis in overall patients with PCNS-DLBCL. However, among patients treated with combined high-dose methotrexate, vincristine and procarbazine and radiotherapy, dual MYC and BCL2 overexpression (a cutoff score of 60) was an independent poor prognostic indicator $(P=0.010)$.
\end{abstract}

Conclusions: Evaluation of MYC and BCL2 expression may be helpful for the determination of PCNS-DLBCL prognosis. Keywords: Primary central nervous system lymphoma, Diffuse large B-cell lymphoma, MYC, BCL2, Prognosis

\footnotetext{
*Correspondence: junarplus@chol.com

${ }^{1}$ Department of Pathology, Seoul National University Hospital, Seoul National

University College of Medicine, 101 Daehak-ro, Jongno-gu, Seoul 03080,

Republic of Korea

${ }^{2}$ The Tumor Immunity Medical Research Center, Seoul National University

College of Medicine, Seoul, Republic of Korea

Full list of author information is available at the end of the article
} 


\section{Background}

Primary diffuse large B-cell lymphoma of the central nervous system (PCNS-DLBCL) is a distinct subtype of DLBCL that primarily arises in the intracranial and intraocular areas [1]. PCNS-DLBCL has a poorer prognosis than systemic DLBCL. This may be due to the fact the blood brain barrier makes it difficult for chemotherapeutic agents to penetrate, that the site of involvement is immune-privileged, and that the cell of origin is mainly a non-germinal center B-cell [2].

To determine the prognosis of PCNS-DLBCL, several scoring systems, which are mostly based on clinical features, have been recommended. The international extranodal lymphoma study group (IELSG) suggested that age ( $>60$ years), performance status (PS) $(\geq 2)$, elevated serum lactate dehydrogenase (LDH) levels, a high cerebrospinal fluid (CSF) protein concentration, and involvement of deep brain structures (periventricular regions, basal ganglia, brain stem, and/or cerebellum) are significantly associated with a poor prognosis. This scoring system was validated in patients treated with high-dose methotrexate-based chemotherapy [3]. In contrast, the Nottingham/Barcelona score, which incorporates age $\geq 60$, PS $\geq 2$ and multifocal disease, showed a prognostic impact in patients treated with CHOD/BVAM or BVAM chemotherapy followed by radiotherapy [4]. Meanwhile, the Memorial Sloan-Kettering Cancer Center (MSKCC) prognostic model is able to classify patients into class 1 (age $\leq 50$ years), class 2 (age $>50$; Karnofsky performance score (KPS) $\geq 70$ ) and class 3 (age $>50$; KPS $<70$ ) with prognostic significance [5]. However, there is still no consensus about prognostic scoring systems in PCNSDLBCL. Moreover, the pathological and biological prognostic factors for PCNS-DLBCL remain unknown.

Recent studies have shown that concomitant MYC and BCL2 expression predicts inferior survival in systemic DLBCL patients treated with rituximab-CHOP $[6,7]$. Moreover, coexpression MYC and BCL2 was found to have prognostic value in patients with DLBCL independent of cell of origin, but is related to a high-risk gene expression signature [7]. Thus, MYC and BCL2 coexpression status is very helpful for risk stratification along with the international prognostic index (IPI) score in systemic DLBCL $[6,7]$. Meanwhile, only a few studies are available on MYC and BCL2 expression in PCNS-DLBCL [8-10]. However, these studies have demonstrated conflicting results in terms of prognostic significance of MYC and BCL2 status in patients with PCNS-DLBCL. A study on 47 patients with PCNS-DLBCL showed that MYC, BCL2 and BCL6 were frequently coexpressed but had no prognostic significance [8]. Another study demonstrated that MYC expression, with or without BCL2 coexpression, was not predictive of clinical outcome in 59 patients with PCNSDLBCL [9]. In contrast, MYC expression was associated with poor prognosis in a study on 42 patients with PCNSDLBCL [10]. Thus, we comprehensively investigated the expression of MYC, BCL2 and BCL6, and their association with clinicopathological characteristics and prognosis in a large cohort of PCNS-DLBCL patients.

\section{Methods \\ Patients}

In total, 114 patients diagnosed with PCNS-DLBCL managed at Seoul National University Hospital (SNUH, Seoul, Korea) between 2000 and 2012 were included in this study. Pathologic diagnosis was performed according to the current World Health Organization (WHO) classification of Tumors of Hematopoietic and Lymphoid Tissues [1]. Tumor tissues were obtained before treatment in all patients. Clinicopathological and survival data were retrieved from medical records by three hemato-oncologists (E.L, T.M.K and D.S.H) and from the review of pathological material by three pathologists (S.K., S.J.N and Y.K.J). This study followed the World Medical Association Declaration of Helsinki recommendations and was approved by the Institutional Review Board (IRB) of SNUH (IRB No. 1506-080-681). Informed consent for participation in the study was waived by the IRB of SNUH on the basis that this study was a retrospective study using archived material and did not pose increased risk to the patients.

\section{Immunohistochemistry}

Immunohistochemistry (IHC) was performed using antibodies against MYC (clone EP121, Cell Marque, Rocklin, CA, USA), BCL2 (clone 124, DAKO, Carpinteria, CA, USA), BCL6 (clone LN22, Novocastra, Newcastle, United Kingdom), CD10 (clone 56C6, Novocastra), and MUM1 (clone Ma695, Novocastra). IHC staining was performed using the Ventana Benchmark XT system (Ventana Medical Systems, Tucson, AZ, USA) or a Bond-Max automated immunostainer (Leica Microsystems, Melbourne, Australia). Cell of origin was assessed according to the Hans criteria [11]. IHC score was determined to be the percentage of tumor cells with robust immunostaining evaluated by $10 \%$ increments. Cutoff values (i.e. IHC scores) of $\geq 40 \%$ for $\mathrm{MYC}, \geq 30$ and $\geq 60 \%$ for BCL2 and $\geq 50 \%$ for BCL6 were determined to have discriminant prognostic power based on the receiver operator characteristic (ROC) curves and were thus used for classifying cases into MYC-, BCL2- or BCL6-negative and-positive groups.

\section{Statistical analysis}

A comparison of clinicopathological parameters was performed by Chi-square, Fisher's exact, and Student's $t$-tests. PFS and OS were analyzed using the Kaplan-Meier method and the log-rank test. Univariate and multivariate 
analysis were performed using the Cox proportional hazards regression model. All statistical analyses were performed using SPSS software (version 21; IBM Corp., Armonk, NY, USA). Two-sided $P$ values $<0.05$ were considered statistically significant.

\section{Results}

Clinicopathological features of patients with PCNS-DLBCL The clinicopathological characteristics and treatment modalities of 114 patients with PCNS-DLBCL are summarized in Table 1. The patient population included 65 (57.0\%) males and 49 (43.0\%) females with a median age of 61 years (range 10-82 years). Most patients had experienced neurologic deficits as the initial symptom (78/114, 68.4\%), and had a KPS score $\geq 70(97 / 111,87.4 \%)$ and an ECOG PS $<2$ $(73 / 112,65.2 \%)$ at diagnosis. Deep structure involvement $(84 / 114,73.7 \%)$ and multifocality $(72 / 114,63.2 \%)$ were frequently observed. The majority $(89 / 113,78.8 \%)$ of cases were of non-germinal center B-cell origin, which was higher than in systemic DLBCL patients in our institute (63\%) [12]. In total, $52.7 \%(48 / 91)$ of patients had an IELSG score $\geq 3,52.7 \%(59 / 112)$ of patients had a Nottingham-Barcelona score $\geq 2$ and $79.8 \%$ (91/112) of patients were classified as MSKCC class 2 or 3. Most patients received high-dose methotrexate-containing chemotherapy including high-dose methotrexate, vincristine and procarbazine (MVP) $(79 / 97,81.4 \%)$ or high-dose methotrexate (HD-MTX) (14/97, 14.4\%), and $58.8 \%$ (57/97) of patients were treated with combined MVP and radiotherapy.

The five-year PFS and OS based on clinicopathological variables are shown in Table 1 . Older patients (age $>60$ ) had a shorter OS $(P=0.014)$, and patients with KSP $<70$ and multifocal lesions had a shorter PFS $(P=0.001$ and 0.037 , respectively). The non-germinal center phenotype tended to have a poorer PFS, but this did not reach statistical significance $(P=0.073)$. Patients with a NottinghamBarcelona score $\geq 2$ or MSKCC class 2 or 3 had a shorter PFS ( $P=0.001$ and 0.008 , respectively). The IELSG scoring system showed inconclusive results, in that patients with an IELSG score $\geq 3$ had a tendency to show better PFS ( $P=$ $0.093)$ and worse OS $(P=0.054)$. The treatment modalities including the chemotherapeutic agent, use of radiotherapy, rituximab or intrathecal-MTX were not associated with patient clinical outcomes in the total patient group. However, in the MVP-treated group, patients receiving radiotherapy showed a better prognosis than did those who did not receive radiotherapy (for PFS, $P=0.078$; for $\mathrm{OS}, P=0.001$ ) (data not shown).

\section{Relationship between MYC, BCL2, and BCL6 expression and clinicopathological features}

Representative IHC images of MYC, BCL2 and BCL6 are shown in Fig. 1. The proportion of tumor cells expressing MYC (i.e., MYC IHC score) was estimated as $18.16 \pm 19.58 \%$ (mean $\pm \mathrm{SD}$ ) (median: 10, range: 0$80 \%)$. Using a cutoff score of 40, 21 (18.1\%) of the 114 cases were placed in the MYC-positive group. The BCL2 IHC score was also measured, with an average score of $58.86 \pm 35.07 \%$ (median: 70, range: $0-100 \%) ; 87(75.0 \%)$ and $68(59.6 \%)$ of the 114 cases were classified as BCL2-positive using cutoff score of 30 and 60, respectively. The average BCL6 IHC score was $39.39 \pm 37.66 \%$ (median: 25 , range: $0-$ $100 \%)$, and $51(44.0 \%)$ of the 114 cases were classified as BCL6-positive using a cutoff score of 50. Taken together, MYC and BCL2 dual-positive cases accounted for $15.8 \%(18 / 114)$ of PCNS-DLBCLs, while MYC and BCL2 dual-negative cases accounted for $21.9 \%(25 / 114)$ with a BCL2 cutoff score of 30 . In addition, MYC and BCL2 IHC scores were positively correlated (Spearman's rho $=0.320, P=0.001$ ), but MYC and BCL6, and BCL2 and BCL6 IHC scores were not (Additional file 1: Figure S1).

Among the 57 patients treated with combined MVP and radiotherapy (MVP-RT hereafter), $12.3 \%$ (7/57) were designated as MYC-positive using a cutoff score of 40 , and $71.9 \%(41 / 57)$ and $54.4 \%(31 / 57)$ of the cases were classified as BCL2-positive using cutoff scores of 30 and 60 , respectively; $49.1 \%$ (28/57) of the cases were classified as BCL6-positive using a cutoff score of 50. Taken together, MYC and BCL2 dualpositive cases accounted for $12.3 \%$ (7/57; with a BCL2 cutoff score of 30$)$ and $10.5 \%$ (6/57; with a BCL2 cutoff score of 60), while MYC and BCL2 dual-negative cases accounted for $28.1 \%$ (16/57; with a BCL2 cutoff score of 30$)$ and $43.9 \%$ (25/57; with a BCL2 cutoff score of 60) of patients in the MVP-RT group.

The relationship between MYC, BCL2 and BCL6 expression and clinicopathological features are summarized in Table 2 and Additional file 2: Table S1. Patients aged $>60$ years tended to be BCL2-positive more often $(P=0.051)$, and higher MSKCC class was significantly associated with MYC and BCL2 positivity separately $(P=0.012$ and 0.008 , respectively) (Table 2$)$ and with MYC and BCL2 coexpression $(P=0.022$ by Fisher's Exact Test) (data not shown). Cases of nongerminal cell origin were BCL2-positive more often $(P=0.005)$, but were BCL6-negative $(P=0.013)$ (Table 2 and Additional file 2: Table S1). There were no other correlations between clinical parameters and MYC, BCL2 or BCL6 expression. In addition, MYC, BCL2 or BCL6 positivity did not differ by treatment modality (data not shown). Among the patients of MVP-RT group, no significant relationship was observed between clinicopathological features and the MYC and BCL2 expression status except for higher expression of MYC in female than in male $(P=0.039)$ (data not shown). 
Table 1 Clinicopathological characteristics of patients and treatment modalities

\begin{tabular}{|c|c|c|c|c|c|c|}
\hline \multirow[t]{2}{*}{ Variables $^{a}$} & & \multirow{2}{*}{$\begin{array}{l}\text { n (\%) } \\
(\text { Total = 114) }\end{array}$} & \multirow{2}{*}{$\begin{array}{l}\text { 5YRS } \\
\text { PFS (SD) }\end{array}$} & \multirow{2}{*}{$\begin{array}{l}\text { PFS, } \\
P^{d}\end{array}$} & \multirow{2}{*}{$\begin{array}{l}\text { 5YRS } \\
\text { OS (SD) }\end{array}$} & \multirow{2}{*}{$\begin{array}{l}\text { OS, } \\
P^{d}\end{array}$} \\
\hline & & & & & & \\
\hline \multirow[t]{2}{*}{ Age (yr) } & $\leq 50$ & $23(20.2)$ & $0.684(0.108)$ & 0.072 & $0.909(0.043)$ & 0.126 \\
\hline & $>50$ & $91(79.8)$ & $0.334(0.090)$ & & $0.698(0.086)$ & \\
\hline \multirow[t]{2}{*}{ Age (yr) } & $\leq 60$ & $55(48.2)$ & $0.498(0.081)$ & 0.585 & $0.854(0.065)$ & 0.014 \\
\hline & $>60$ & $59(51.8)$ & $0.217(0.167)$ & & $0.569(0.172)$ & \\
\hline \multirow[t]{2}{*}{ Sex } & M & $65(57.0)$ & $0.452(0.086)$ & 0.708 & $0.849(0.054)$ & 0.156 \\
\hline & $\mathrm{F}$ & $49(43.0)$ & $0.460(0.112)$ & & $0.452(0.168)$ & \\
\hline \multirow[t]{3}{*}{ Initial Symptoms } & Headache \&vomiting & $30(26.3)$ & $0.609(0.114)$ & 0.400 & $0.870(0.071)$ & 0.266 \\
\hline & Seizure & $6(5.3)$ & $0.000(0.000)$ & & 100.0 & \\
\hline & Neurologic deficit & $78(68.4)$ & $0.387(0.085)$ & & $0.697(0.085)$ & \\
\hline \multirow[t]{2}{*}{ ECOG PS } & 0,1 & $73(65.2)$ & $0.425(0.086)$ & 0.818 & $0.789(0.075)$ & 0.247 \\
\hline & $2-4$ & $39(34.8)$ & $0.511(0.135)$ & & $0.752(0.079)$ & \\
\hline \multirow[t]{2}{*}{ KPS } & $\geq 70$ & $97(87.4)$ & $0.468(0.082)$ & 0.001 & $0.760(0.065)$ & 0.854 \\
\hline & $<70$ & $14(12.6)$ & $0.259(0.144)$ & & $0.821(0.117)$ & \\
\hline \multirow[t]{2}{*}{ B Symptoms } & Absent & 109 (95.6) & $0.452(0.073)$ & 0.284 & $0.768(0.061)$ & 0.558 \\
\hline & Present & $5(4.4)$ & $0.333(0.272)$ & & $0.800(0.179)$ & \\
\hline \multirow[t]{2}{*}{ Serum LDH } & Normal & $68(63.6)$ & $0.223(0.087)$ & 0.005 & $0.767(0.102)$ & 0.201 \\
\hline & Elevated & $39(36.4)$ & $0.675(0.102)$ & & $0.760(0.100)$ & \\
\hline \multirow[t]{2}{*}{ Cell of origin } & GCB & $24(21.2)$ & $0.689(0.120)$ & 0.073 & $0.795(0.092)$ & 0.957 \\
\hline & Non-GCB & $89(78.8)$ & $0.383(0.082)$ & & $0.756(0.074)$ & \\
\hline \multirow[t]{2}{*}{ Involvement of deep structure } & Absent & $30(26.3)$ & $0.441(0.161)$ & 0.219 & $0.758(0.129)$ & 0.640 \\
\hline & Present & $84(73.7)$ & $0.433(0.078)$ & & $0.762(0.070)$ & \\
\hline \multirow[t]{2}{*}{ Extent of disease } & Unifocal & $42(36.8)$ & $0.553(0.119)$ & 0.037 & $0.753(0.137)$ & 0.603 \\
\hline & Multifocal & $72(63.2)$ & $0.368(0.088)$ & & $0.782(0.062)$ & \\
\hline \multirow[t]{2}{*}{ Ocular involvement } & Absent & $101(89.4)$ & $0.485(0.072)$ & 0.985 & $0.872(0.046)$ & 0.466 \\
\hline & Present & $12(10.6)$ & $0.233(0.190)$ & & $0.525(0.204)$ & \\
\hline \multirow[t]{2}{*}{ CSF protein } & Normal & $39(42.4)$ & $0.291(0.142)$ & 0.988 & $0.675(0.141)$ & 0.340 \\
\hline & Elevated & $53(57.6)$ & $0.467(0.090)$ & & $0.849(0.058)$ & \\
\hline \multirow[t]{2}{*}{ CSF cytology } & Negative & $82(85.4)$ & $0.356(0.083)$ & 0.281 & $0.774(0.066)$ & 0.693 \\
\hline & Positive & $14(14.6)$ & $0.608(0.158)$ & & $0.711(0.180)$ & \\
\hline \multirow[t]{2}{*}{ IELSG } & $0-2$ & $43(47.3)$ & $0.229(0.100)$ & 0.093 & $0.853(0.101)$ & 0.054 \\
\hline & $3-5$ & $48(52.7)$ & $0.638(0.088)$ & & $0.736(0.074)$ & \\
\hline \multirow[t]{2}{*}{ Nottingham- Barcelona } & $0-1$ & $53(47.3)$ & $0.604(0.097)$ & 0.001 & $0.807(0.080)$ & 0.188 \\
\hline & $2-3$ & $59(52.7)$ & $0.264(0.098)$ & & $0.723(0.084)$ & \\
\hline \multirow[t]{2}{*}{ MSKCC class } & 1 & $21(18.4)$ & $0.760(0.106)$ & 0.008 & $0.847(0.108)$ & 0.157 \\
\hline & $2-3$ & $91(79.8)$ & $0.340(0.086)$ & & $0.688(0.095)$ & \\
\hline \multirow[t]{2}{*}{ Radiotherapy } & Not done & $36(31.6)$ & $0.586(0.142)$ & 0.854 & $0.758(0.086)$ & 0.057 \\
\hline & Done & $78(68.4)$ & $0.416(0.080)$ & & $0.787(0.068)$ & \\
\hline \multirow[t]{3}{*}{ Chemotherapy } & $M V P^{b}$ & $79(81.4)$ & $0.431(0.084)$ & 0.519 & $0.772(0.072)$ & 0.940 \\
\hline & HD-MTX & $14(14.4)$ & $0.442(0.176)$ & & $0.791(0.138)$ & \\
\hline & Others ${ }^{c}$ & $4(4.1)$ & $0.750(0.217)$ & & 100.0 & \\
\hline
\end{tabular}


Table 1 Clinicopathological characteristics of patients and treatment modalities (Continued)

\begin{tabular}{|c|c|c|c|c|c|c|}
\hline \multirow[t]{2}{*}{$\overline{R i t u x i m a b}$} & Not done & $103(90.4)$ & $0.453(0.074)$ & 0.756 & $0.748(0.067)$ & 0.503 \\
\hline & Done & $11(9.6)$ & $0.333(0.248)$ & & $0.909(0.087)$ & \\
\hline \multirow[t]{2}{*}{ IT-MTX } & Not done & 89 (78.1) & $0.412(0.092)$ & 0.649 & $0.743(0.076)$ & 0.415 \\
\hline & Done & 25 (21.9) & $0.457(0.114)$ & & $0.832(0.089)$ & \\
\hline
\end{tabular}

Abbreviations: ECOG PS The Eastern Cooperative Oncology Group performance score, KPS Karnofsky performance status score, $L D H$ lactate dehydrogenase, GCB germinal center B cell-like, CSF cerebrospinal fluid, IELSG the International Extranodal Lymphoma Study group, MSKCC Memorial Sloan Kettering Cancer Center, MVP combined chemotherapy regimen of high-dose methotrexate, vincristine and procarbazine, HD-MTX high-dose methotrexate, IT-MTX intrathecal methotrexate, PFS progression-free survival, OS overall survival

${ }^{a}$ Some cases have missing values that lacked the information about the variables bIncludes 8 patients who received rituximab-MVP

'Others include COPADM and CHOP

${ }^{d}$ PFS and OS were analyzed using the Kaplan-Meier method with the log-rank test

\section{Prognostic significance of MYC, BCL2 and BCL6 expression}

Kaplan-Meier survival analysis demonstrated that MYC expression (cutoff score 40) was significantly associated with a shorter PFS $(P=0.027)$ in patients with PCNSDLBCL (Fig. 2a), but not with OS (Fig. 2b). In contrast, higher BCL2 expression was significantly related to a shorter OS $(P=0.010$ with a cutoff score of 30 and $P=$ 0.031 with a cutoff score 60 ), but was not related to PFS (Fig. 2c-f). BCL6 expression had no prognostic significance. Patients who were negative for both MYC and BCL2 (cutoff score 30) showed better OS than patients positive for either $(P=0.014)$ (Fig. 3a and b). Patients with dual positivity for MYC and BCL2 (cutoff score 30) exhibited worse PFS than that of the others $(P=0.041)$ (Fig. 3c and d), but its statistical significance was lower than that observed by comparing MYC expression status alone (Fig. 2a). After incorporating both age and prognostic score into a multivariate analysis, MYC and BCL2 expression lost its prognostic impact, and a higher Nottingham-Barcelona score $(\geq 2)$ and age remained as independent prognostic indicators for PFS $(P=0.032)$ and $\operatorname{OS}(P=0.044)$, respectively (Table 3$)$.

Among patients with PCNS-DLBCL treated with MVPRT, MYC expression (cutoff score of 40) was associated with a shorter PFS $(P=0.011)$ (Additional file 3: Figure $S 2)$. BCL2 overexpression (cutoff score of 60 ) was significantly related to a shorter OS $(P=0.025)$ (Additional file 3: Figure $\mathrm{S} 2$ ). In the MVP-RT group, patients with dual positivity for MYC and BCL2 (cutoff score of 60) exhibited worse PFS than that of the others $(P<0.001)$ (Fig. 3e), and those who were negative for both MYC and BCL2 (cutoff score of 60) showed better OS than that of patients positive for either $(P=0.033)$ (Fig. 3f). Furthermore, in multivariate analysis, MYC and BCL2 coexpression was an independent factor for poor PFS $(P=0.010$; hazard ratio $=4.372)$ (Table 4).

\section{Discussion}

This study demonstrated that MYC and BCL2 overexpression was significantly associated with a high MSKCC class, and was related to shorter PFS and OS in patients with PCNS-DLBCL.

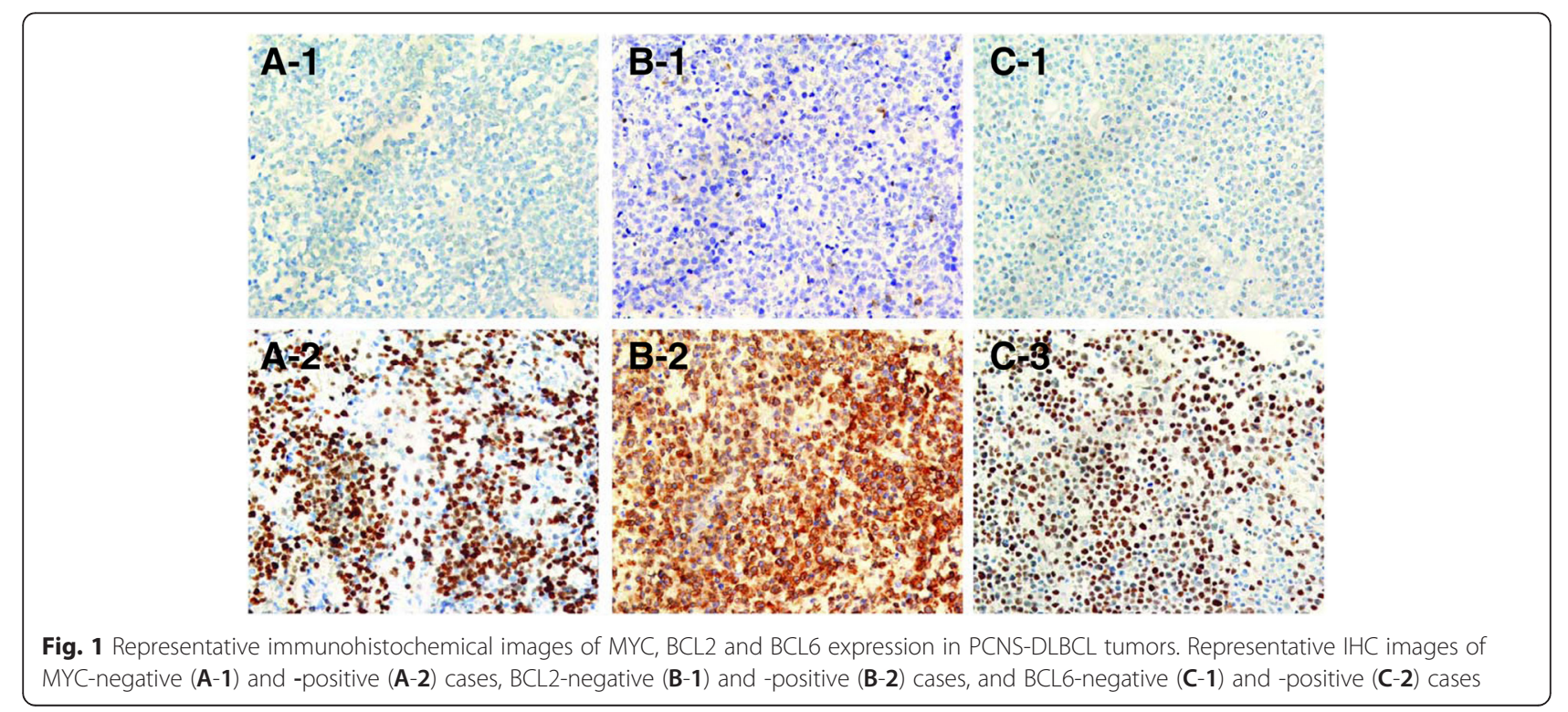


Table 2 Correlation of MYC and BCL2 expression and clinicopathological variables

\begin{tabular}{|c|c|c|c|c|c|c|c|}
\hline \multirow{2}{*}{ Variables $^{a}$} & & \multicolumn{2}{|l|}{ MYC, n (\%) } & \multicolumn{4}{|c|}{ BCL2, n (\%) } \\
\hline & & $<40$ & $\geq 40$ & $\bar{P}$ & $<30$ & $\geq 30$ & $P$ \\
\hline Age (yr) & mean $\pm S D$ & $57.6 \pm 14.6$ & $63.1 \pm 7.6$ & 0.097 & $50.4 \pm 19$ & $61.3 \pm 10.4$ & $<0.001$ \\
\hline \multirow[t]{2}{*}{ Age (yr) } & $\leq 50$ & $22(95.7)$ & $1(4.3)$ & 0.069 & $11(47.8)$ & $12(52.2)$ & 0.004 \\
\hline & $>50$ & $71(78)$ & $20(22)$ & & 17 (18.7) & $74(81.3)$ & \\
\hline \multirow[t]{2}{*}{ Age (yr) } & $\leq 60$ & $46(83.6)$ & $9(16.4)$ & 0.584 & $18(32.7)$ & $37(67.3)$ & 0.051 \\
\hline & $>60$ & $47(79.7)$ & $12(20.3)$ & & $10(16.9)$ & $49(83.1)$ & \\
\hline \multirow[t]{2}{*}{ Sex } & M & 55 (84.6) & $10(15.4)$ & 0.335 & $20(30.8)$ & $45(69.2)$ & 0.076 \\
\hline & $\mathrm{F}$ & $38(77.6)$ & $11(22.4)$ & & $8(16.3)$ & $41(83.7)$ & \\
\hline \multirow[t]{2}{*}{ ECOG PS } & 0,1 & $62(84.9)$ & $11(15.1)$ & 0.172 & $19(26)$ & $54(74)$ & 0.731 \\
\hline & $2-4$ & $29(74.4)$ & $10(25.6)$ & & $9(23.1)$ & $30(76.9)$ & \\
\hline \multirow[t]{2}{*}{ KPS } & $\geq 70$ & $81(83.5)$ & $16(16.5)$ & 0.136 & $24(24.7)$ & $73(75.3)$ & $>0.999$ \\
\hline & $<70$ & $9(64.3)$ & $5(35.7)$ & & $3(21.4)$ & 11 (78.6) & \\
\hline \multirow[t]{2}{*}{ B symptoms } & Absent & $88(80.7)$ & $21(19.3)$ & $0.582^{b}$ & $26(23.9)$ & $83(76.1)$ & $0.595^{\mathrm{b}}$ \\
\hline & Present & $5(100)$ & $0(0)$ & & $2(40)$ & $3(60)$ & \\
\hline \multirow[t]{2}{*}{ Serum LDH } & Normal & $54(79.4)$ & $14(20.6)$ & 0.506 & 19 (27.9) & $49(72.1)$ & 0.582 \\
\hline & Elevated & $33(84.6)$ & $6(15.4)$ & & $9(23.1)$ & $30(76.9)$ & \\
\hline \multirow[t]{2}{*}{ Cell of origin } & GCB & $22(91.7)$ & $2(8.3)$ & $0.236^{b}$ & $11(45.8)$ & $13(54.2)$ & 0.005 \\
\hline & Non-GCB & 70 (78.7) & 19 (21.3) & & $16(18)$ & $73(82)$ & \\
\hline \multirow[t]{2}{*}{ Involvement of deep structure } & Absent & $24(80)$ & $6(20)$ & 0.795 & $6(20)$ & $24(80)$ & 0.499 \\
\hline & Present & $69(82.1)$ & $15(17.9)$ & & $22(26.2)$ & $62(73.8)$ & \\
\hline \multirow[t]{2}{*}{ Extent of disease } & Unifocal & $34(81)$ & $8(19)$ & 0.895 & $11(26.2)$ & $31(73.8)$ & 0.758 \\
\hline & Multifocal & $59(81.9)$ & $13(18.1)$ & & $17(23.6)$ & $55(76.4)$ & \\
\hline \multirow[t]{2}{*}{ Ocular involvement } & Absent & $82(81.2)$ & $19(18.8)$ & $>0.999^{\mathrm{b}}$ & $25(24.8)$ & $76(75.2)$ & $>0.999^{\mathrm{b}}$ \\
\hline & Present & $10(83.3)$ & $2(16.7)$ & & $3(25)$ & $9(75)$ & \\
\hline \multirow[t]{2}{*}{ CSF protein } & Normal & $31(79.5)$ & $8(20.5)$ & 0.844 & $8(20.5)$ & $31(79.5)$ & 0.157 \\
\hline & Elevated & $43(81.1)$ & $10(18.9)$ & & $18(34.0)$ & $35(66.0)$ & \\
\hline \multirow[t]{2}{*}{ CSF cytology } & Negative & $66(80.5)$ & $16(19.5)$ & $>0.999^{b}$ & $19(23.2)$ & $63(76.8)$ & 0.121 \\
\hline & Positive & $11(78.6)$ & $3(21.4)$ & & $6(42.9)$ & $8(57.1)$ & \\
\hline \multirow[t]{2}{*}{ IELSG } & $0-2$ & $35(81.4)$ & $8(18.6)$ & 0.790 & $13(30.2)$ & $30(69.8)$ & 0.740 \\
\hline & $3-5$ & $38(79.2)$ & $10(20.8)$ & & $13(27.1)$ & $35(72.9)$ & \\
\hline \multirow[t]{2}{*}{ Nottingham- Barcelona } & $0-1$ & $46(86.8)$ & $7(13.2)$ & 0.154 & $16(30.2)$ & $37(69.8)$ & 0.229 \\
\hline & $2-3$ & $45(76.3)$ & $14(23.7)$ & & $12(20.3)$ & 47(79.7) & \\
\hline \multirow[t]{2}{*}{ MSKCC class } & 1 & $21(100)$ & $0(0)$ & $0.012^{b}$ & $10(47.6)$ & $11(52.4)$ & 0.008 \\
\hline & $2-3$ & 70 (76.9) & $21(23.1)$ & & 18 (19.8) & $73(80.2)$ & \\
\hline
\end{tabular}

Abbreviations: ECOG PS The Eastern Cooperative Oncology Group performance score, KPS Karnofsky performance status score, $L D H$ lactate dehydrogenase, GCB germinal center B cell-like, CSF cerebrospinal fluid, IELSG the International Extranodal Lymphoma Study group, MSKCC Memorial Sloan Kettering Cancer Center ${ }^{a}$ Some cases have missing values that lacked the information about the variables ${ }^{\mathrm{b}}$ Fisher's exact test

This study showed that MYC overexpression was associated with poor PFS in PCNS-DLBCL, which was partly consistent with Tapia et al.'s study [10], but different from previous reports by Brunn et al. and Gill et al. [8, 9]. Tapia et al. reported that MYC overexpression (using a cutoff score of 30) was related to poor OS, while the latter studies showed that MYC expression was not associated with PCNS-
DLBCL prognosis. In this study, the mean MYC expression score was $18.16 \pm 19.58$ and the MYC positive rate using a cutoff score of 40 was $18.1 \%$, which were much lower than those observed in previous reports. Previous studies on PCNS-DLBCL reported a mean MYC expression score of 29-50 and MYC positive rates ranging from 43 to $82 \%$ with cutoff values of 30 or 40, and an unreported cutoff score in one 

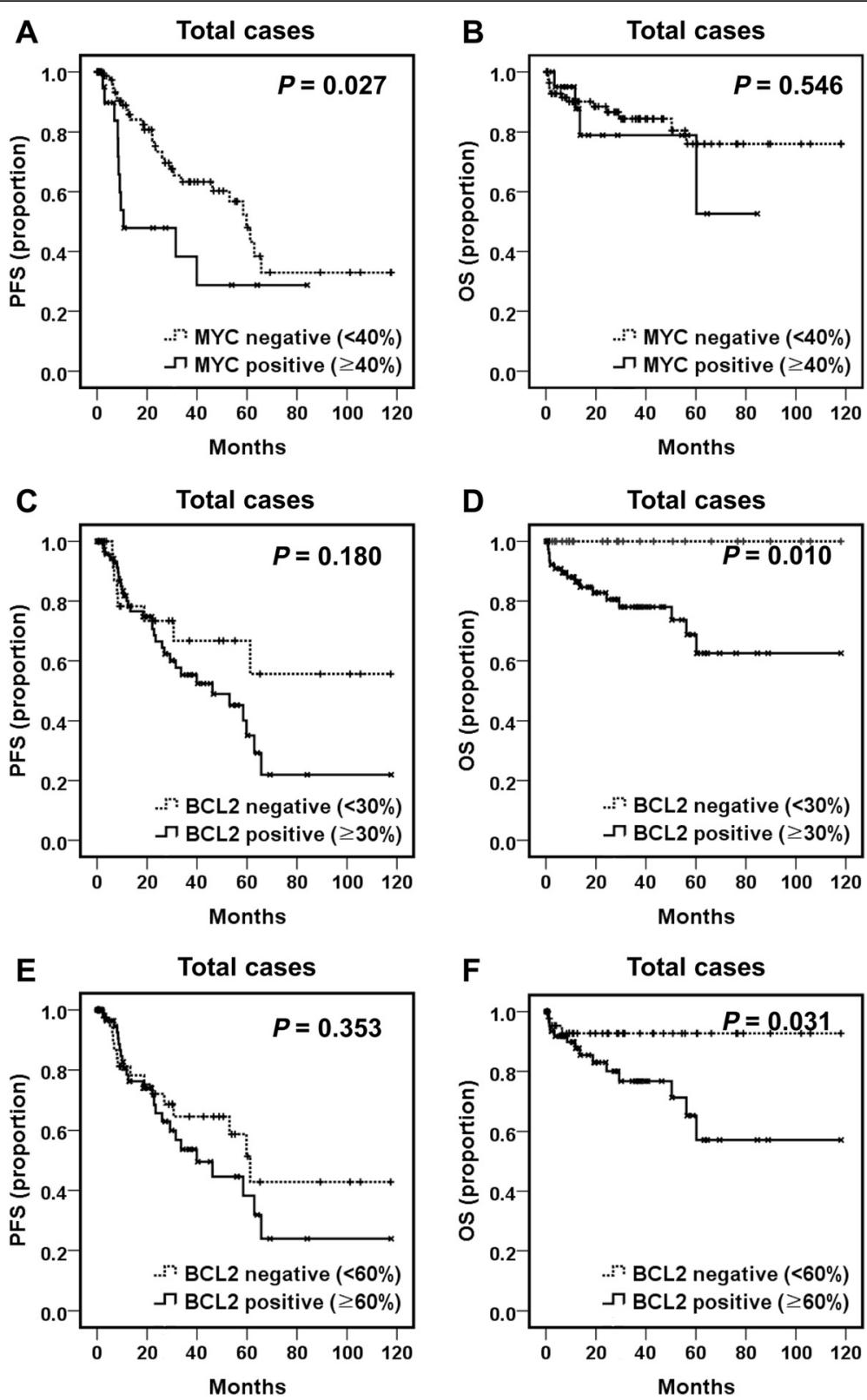

Fig. 2 Progression-free survival (PFS) and overall survival (OS) of patients with PCNS-DLBCL according to MYC or BCL2 expression status. a and $\mathbf{b}$ PFS and OS according to MYC protein expression status (cutoff score 40) are plotted using the Kaplan-Meier method and analyzed by the log-rank test. PFS and OS according to BCL2 protein expression status using a cutoff score of 30 (c and $\mathbf{d}$ ), or with a cutoff score of 60 (e and $\mathbf{f}$ ) are plotted using the Kaplan-Meier method and analyzed by the log-rank test

case [8-10]. However, antibody and racial differences (Western $v s$. Asian) may account for these discrepancies.

MYC immunostaining in systemic DLBCLs, particularly in cases without MYC gene translocation, is heterogeneous. Thus, the feasibility of interpreting and scoring MYC expression using IHC in DLBCL has been questioned [13]. We performed $M Y C$ fluorescence in situ hybridization in PCNS-DLBCL cases with MYC overexpression as reported previously [14]. Of note, in this study, only 2 (12\%) of 17 patients with MYC overexpression had a $M Y C$ translocation, and another two patients showed increased $M Y C$ copy number (ICN) (Additional file 2: Table S2). In contrast, approximately $25 \%$ of the MYC overexpressing systemic DLBCLs showed MYC gene translocation [15]. Thus, translocation and ICN did not appear to explain MYC overexpression in most cases of PCNSDLBCL, consistent with a previous report [10]. MYC overexpression in PCNS-DLBCL might result from other mechanisms such as a mutation of $M Y C$ and posttranscriptional or post-translational regulation. In addition, 

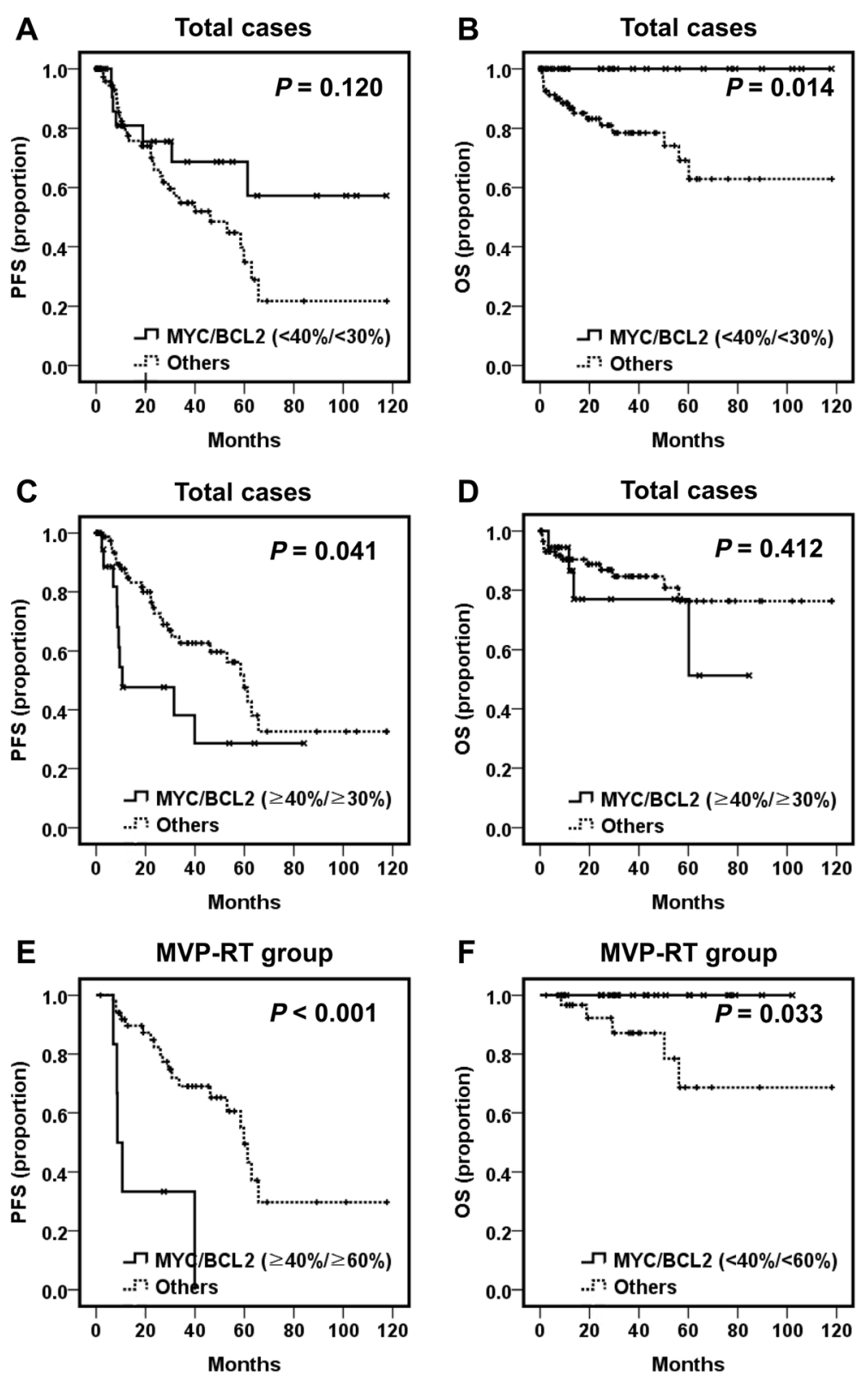

Fig. 3 Progression-free survival (PFS) and overall survival (OS) of patients with PCNS-DLBCL according to combined MYC and BCL2 expression status. a and $\mathbf{b}$ PFS and OS of patients without expression for either MYC or BCL2 (double-negative) versus other groups are plotted using the Kaplan-Meier method and analyzed by the log-rank test. $\mathbf{c}$ and $\mathbf{d}$ PFS and OS of patients with concomitant MYC and BCL2 expression (double-positive) versus other groups are plotted using the Kaplan-Meier method and analyzed by the log-rank test. e and $\mathbf{f}$ PFS and OS of patients treated with combined MVP and radiotherapy according to the MYC and BCL2 expression status were plotted using the Kaplan-Meier method and analyzed by the log-rank test

post-genetic or epigenetic regulation of MYC expression in PCNS-DLBCL may lead to heterogeneous MYC immunostaining. Meanwhile, concordance of MYC scoring between hematopathologists was much lower when interpreting entire tissue sections rather than a tissue microarray using a 1-mm core [13]. In this study, whole tissue sections were used and the largest series of patients with PCNS-DLBCL was evaluated based on treatment modality, and MYC overexpression was found to have prognostic value.

The rate of BCL2 expression in PCNS-DLBCL varies, which might also be attributable to the use of different antibodies and different cutoff values for determining overexpression [8, 9, 16-19]. Previous studies reported a wide range of BCL2 expression rates (56-92\%) with various cutoff scores from 25-70. We observed that 
Table 3 Multivariate analysis of MYC expression and prognostic scoring systems for progression-free survival and overall survival in all patients with PCNS-DLBCL

\begin{tabular}{|c|c|c|c|c|c|c|c|}
\hline & \multicolumn{3}{|l|}{ PFS } & \multicolumn{4}{|l|}{ OS } \\
\hline & $\overline{\mathrm{HR}}$ & $95 \% \mathrm{Cl}$ & $P$ & & $\mathrm{HR}$ & $95 \% \mathrm{Cl}$ & $P$ \\
\hline$\overline{\text { Age }}$ & 0.989 & $0.949-1.032$ & 0.614 & Age & 1.074 & $1.002-1.151$ & 0.044 \\
\hline$M Y C \geq 40$ & 1.745 & $0.848-3.589$ & 0.130 & $\mathrm{BCL} 2 \geq 30$ & $--^{a}$ & $--^{a}$ & 0.951 \\
\hline$N-B, 2-3$ & 2.243 & $1.072-4.693$ & 0.032 & $N-B, 2-3$ & 1.392 & $0.474-4.084$ & 0.547 \\
\hline MSKCC, 2-3 & 2.635 & $0.502-13.827$ & 0.252 & MSKCC, 2-3 & 0.370 & $0.048-2.841$ & 0.339 \\
\hline
\end{tabular}

Abbreviations: PFS progression-free survival, OS overall survival, $H R$ hazard ratio, $C l$ confidence interval, $N-B$ Nottingham-Barcelona, MSKCC Memorial Sloan Kettering Cancer Center

('avalues are not shown.)

$75.0 \%(87 / 114)$ of PCNS-DLBCL cases were BCL2positive using a cutoff score of 30 , similar to a previous report by Tapia et al. [10]. In their study, BCL2 positivity was observed in $71 \%$ of PCNS-DLBCL cases, but had no relationship with prognosis [10]. In contrast, the present study demonstrated that patients with PCNSDLBCL and BCL2 overexpression tended to have a shorter PFS and had significantly poorer OS, suggesting that BCL2 may potentially be used as a prognostic marker.

In this study, MYC and BCL2 expression lost their prognostic significance after multivariate analysis. This may be partly attributable to the fact that MYC and BCL2 expression was significantly associated with higher MSKCC class. The MYC and BCL2 coexpression rate was $15.8 \%(18 / 114)$ of PCNS-DLBCLs, which was much lower than values from previous studies including $29 \%(12 / 41), 60 \%(35 / 59)$ and $82 \%(41 / 50)$ of PCNS-DLBCLs and $34 \%(157 / 466)$ of systemic DLBCLs [7-10], but was similar to the rate (21\% [64/ 304]) reported in another study on systemic DLBCLs [6]. In this study, patients with PCNS-DLBCL and concomitant MYC and BCL2 overexpression showed poor PFS $(P=0.041)$, and those lacking both MYC and BCL2 overexpression had a prolonged OS $(P=0.014)$. However, the statistical significance of MYC and BCL2 dual-positivity on the PFS of patients was diminished

Table 4 Multivariate analysis of MYC and BCL2 coexpression and prognostic scoring systems for progression-free survival in patients with PCNS-DLBCL treated with combined MVP and radiotherapy

\begin{tabular}{|c|c|c|c|}
\hline & \multicolumn{3}{|l|}{ PFS } \\
\hline & $\mathrm{HR}$ & $95 \% \mathrm{Cl}$ & $P$ \\
\hline Age & 0.983 & $0.922-1.049$ & 0.605 \\
\hline$N-B, 2-3$ & 1.146 & $0.464-2.830$ & 0.768 \\
\hline MSKCC, 2-3 & 4.975 & $0.715-34.613$ & 0.105 \\
\hline MYC $(\geq 40)$ and BCL2 ( $\geq 60)$, dual positive & 4.372 & $1.430-13.367$ & 0.010 \\
\hline
\end{tabular}

Abbreviations: PFS progression-free survival, $H R$ hazard ratio, $\mathrm{Cl}$ confidence interval, $N-B$ Nottingham- Barcelona, MSKCC Memorial Sloan Kettering Cancer Center compared to MYC positivity alone $(P=0.027)$. Similar to the present study, Tapia et al. reported that high MYC expression was associated with a lower OS, but that concurrent expression of MYC and BCL2 showed a tendency towards a lower OS with no statistical significance [10]. However, in this study, when analyzed in patients with PCNS-DLBCL treated with combined MVP and radiotherapy, MYC and BCL2 dual-positivity was an independent prognostic factor for poor PFS. Thus, MYC and BCL2 coexpression in PCNS-DLBCL seems to have prognostic value, although it is limited compared with systemic DLBCL.

Several previous studies are available on BCL6 expression and its prognostic impact on PCNS-DLBCL. BCL6 expression rates from 46 to $79 \%$ of PCNSDLBCL cases with cutoff scores from 10-60 have been reported $[16,18,20-22]$. The prognostic implications of BCL6 for PCNS-DLBCL are largely conflicting $[10,16,19-25]$. The results of this study further suggest that BCL6 may have little, if any, prognostic value for PCNS-DLBCL. Non-GCB phenotype tumors were the predominant PCNS-DLBCL type in this study, and no association between cell of origin and prognosis was found, which is consistent with previous reports [9, 26, 27]. Unexpectedly, patients with high serum LDH levels had a more favorable PFS than that of patients with normal serum LDH levels. In addition, the results of this study show that alleged prognostic scoring systems, including Nottingham-Barcelona and MSKCC, reflect PFS but not OS. The reason for these discrepancies is not known, and we were unable to deduce the reasons over the course of this study; however, these results might support the idea that PCNS-DLBCL prognosis is dependent on multiple, complex factors. This study has some limitations. It was a retrospective study, and therapeutic modalities were not completely homogeneous between patients. However, to the best of our knowledge, this study is the largest performed on the expression of MYC, BCL2 and BCL6 PCNS-DLBCL with long-term follow up, and the first report on the 
relationship of these factors to clinicopathological features in Asian patients.

\section{Conclusions}

This study demonstrated that the expression of MYC and BCL2 may be of prognostic value in patients with PCNS-DLBCL when combined with existing prognostic tools and factors.

\section{Additional files}

Additional file 1: Figure S1. Correlation of MYC, BCL2 and BCL6 $1 \mathrm{HC}$ score. Correlations between MYC and BCL2 (left upper), MYC and BCL6 (right upper), and BCL2 and BCL6 (lower) IHC score was compared using Spearman correlation test. (PPT $343 \mathrm{~kb}$ )

Additional file 2: Table S1. Correlation of BCL6 expression and clinicopathological variables; Table S2. MYC translocation and copy number change in MYC positive cases. (DOCX $24 \mathrm{~kb}$ )

Additional file 3: Figure S2. Progression-free survival (PFS) and overall survival (OS) of patients with PCNS-DLBCL treated with MVP-RT according to MYC or BCL2 expression status. (A and B) PFS and OS according to MYC protein expression status (cutoff score 40 ) are plotted using the Kaplan-Meier method and analyzed by the log-rank test. PFS and OS according to BCL2 protein expression status using a cutoff score of 30 ( $C$ and $D)$, or with a cutoff score of 60 ( $E$ and F) are plotted using the Kaplan-Meier method and analyzed by the log-rank test. (TIF $12287 \mathrm{~kb}$ )

Additional file 4: Dataset of 114 patients with PCNS-DLBCL. (XLSX 56 kb)

\section{Abbreviations}

CHOD/BVAM, cyclophosphamide, doxorubicin, vincristine and dexamethasone/ bis-chloronitrosourea, cytosine arabinoside and methotrexate; CHOP, cyclophosphamide, doxorubicin, vincristine and prednisone; $\mathrm{Cl}$, confidence interval; CNS, central nervous system; COPADM, cyclophosphamide, vincristine, prednisolone, doxorubicin and methotrexate; CSF, cerebrospinal fluid; DLBCL, diffuse large B-cell lymphoma; ECOG PS, The Eastern Cooperative Oncology Group performance score; GCB, germinal center B-cell-like; GTR, grossly total resection; HD-MTX, high-dose methotrexate; HR, hazard ratio; IELSG, The international extranodal lymphoma study group; IHC, immunohistochemistry; IPI, international prognostic index; IT-MTX, intrathecal methotrexate; KPS, Karnofsky Performance Status score; LDH, lactate dehydrogenase; MSKCC, Memorial Sloan-Kettering Cancer Center; MVP, combined chemotherapy regimen of high-dose methotrexate, vincristine and procarbazine; N-B, Nottingham- Barcelona; OS, overall survival; PCNSDLBCL, primary diffuse large B-cell lymphoma of the central nervous system; PFS, progression-free survival; RT, radiotherapy; STR, subtotal resection; WHO, World Health Organization; yr, year

\section{Acknowledgements}

Not applicable.

\section{Funding}

This research was supported by the Basic Science Research Program (grant No.: NRF-2013R1A1A2013210) and the Global Core Research Center (GCRC) (grant No. 2012-0001 190) through the National Research Foundation (NRF) funded by the Ministry of Education, Science and Technology (MEST), Republic of Korea.

\section{Availability of data and materials}

The dataset supporting the conclusions of this article is included within the article and its additional file (Additional file 4: Dataset of 114 patients with PCNS-DLBCL (XLSX 60.6 kb)).

\section{Authors' contributions}

SK, SJN, and YKJ designed research, acquired pathologic data, analyzed pathologic and clinical data and wrote the manuscript; DW, HK, SHP, and CWK acquired and analyzed pathologic data and wrote the manuscript; EL, TMK, and DSH acquired and analyzed clinical data, and wrote the manuscript. All authors read and approved the final manuscript.

\section{Authors' information}

Not further applicable.

\section{Competing interests}

The authors declare that they have no competing interests.

\section{Consent for publication}

Not applicable.

\section{Ethics approval and consent to participate}

This study followed the World Medical Association Declaration of Helsinki recommendations and was approved by the Institutional Review Board (IRB) of Seoul National University Hospital (SNUH) (IRB No. 1506-080-681). Informed consent for participation in the study was waived by the IRB of SNUH on the basis that this study was a retrospective study using archived material and did not pose increased risk to the patients.

\section{Author details}

'Department of Pathology, Seoul National University Hospital, Seoul National University College of Medicine, 101 Daehak-ro, Jongno-gu, Seoul 03080, Republic of Korea. ${ }^{2}$ The Tumor Immunity Medical Research Center, Seoul National University College of Medicine, Seoul, Republic of Korea. ${ }^{3}$ Tumor Microenvironment Global Core Research Center, Seoul National University, Seoul, Republic of Korea. ${ }^{4}$ Department of Pathology, Asan Medical Center, Seoul, Republic of Korea. ${ }^{5}$ Department of Internal Medicine, Seoul National University Hospital, Seoul National University College of Medicine, Seoul, Republic of Korea.

Received: 1 December 2015 Accepted: 3 June 2016 Published online: 10 June 2016

\section{References}

1. Swerdlow SH, International Agency for Research on C, World Health O. WHO classification of tumours of haematopoietic and lymphoid tissues. Lyon: International Agency for Research on Cancer; 2008.

2. Bhagavathi $S$, Sharathkumar $A$, Hunter $S$, Sung L, Kanhere R, Venturina MD, Wilson JD Activated B-cell immunophenotype might be associated with poor prognosis of primary central nervous system lymphomas. Clinical neuropathology. 2008;27(1):13-20.

3. Ferreri AJ, Blay JY, Reni M, Pasini F, Spina M, Ambrosetti A, Calderoni A, Rossi A, Vavassori V, Conconi A, et al. Prognostic scoring system for primary CNS Iymphomas: the International Extranodal Lymphoma Study Group experience. Journal of clinical oncology : official journal of the American Society of Clinical Oncology. 2003;21 (2):266-72.

4. Bessell EM, Graus F, Lopez-Guillermo A, Lewis SA, Villa S, Verger E, Petit J. Primary non-Hodgkin's lymphoma of the CNS treated with CHOD/BVAM or BVAM chemotherapy before radiotherapy: long-term survival and prognostic factors. International journal of radiation oncology, biology, physics. 2004:59(2):501-8.

5. Abrey LE, Ben-Porat L, Panageas KS, Yahalom J, Berkey B, Curran W, Schultz C, Leibel S, Nelson D, Mehta M, et al. Primary central nervous system lymphoma: the Memorial Sloan-Kettering Cancer Center prognostic model. Journal of clinical oncology : official journal of the American Society of Clinical Oncology. 2006;24(36):5711-5.

6. Johnson NA, Slack GW, Savage KJ, Connors JM, Ben-Neriah S, Rogic S, Scott DW, Tan KL, Steidl C, Sehn LH, et al. Concurrent expression of MYC and $B C L 2$ in diffuse large B-cell lymphoma treated with rituximab plus cyclophosphamide, doxorubicin, vincristine, and prednisone. Journal of clinical oncology : official journal of the American Society of Clinical Oncology. 2012;30(28):3452-9.

7. Hu S, Xu-Monette ZY, Tzankov A, Green T, Wu L, Balasubramanyam A, Liu WM, Visco C, Li Y, Miranda RN, et al. MYC/BCL2 protein coexpression contributes to the inferior survival of activated B-cell subtype of diffuse large B-cell lymphoma and demonstrates high-risk gene expression signatures: a report from The International DLBCL Rituximab-CHOP Consortium Program. Blood. 2013; 121(20):4021-31.

8. Brunn A, Nagel I, Montesinos-Rongen M, Klapper W, Vater I, Paulus W, Hans V, Blumcke I, Weis J, Siebert R, et al. Frequent triple-hit expression of MYC, BCL2, and BCL6 in primary lymphoma of the central nervous system and absence of a favorable MYC(low)BCL2 (low) subgroup may underlie the inferior prognosis 
as compared to systemic diffuse large B cell lymphomas. Acta neuropathologica. 2013;126(4):603-5.

9. Gill KZ, Iwamoto F, Allen A, Hoehn D, Murty W, Alobeid B, Bhagat G. MYC protein expression in primary diffuse large B-cell lymphoma of the central nervous system. PloS one. 2014;9(12):e114398.

10. Tapia G, Baptista MJ, Munoz-Marmol AM, Gaafar A, Puente-Pomposo M, Garcia O, Garcia O, Marginet-Flinch R, Sanz C, Navarro JT, Sancho JM, et al. MYC protein expression is associated with poor prognosis in primary diffuse large B-cell lymphoma of the central nervous system. APMIS : acta pathologica, microbiologica, et immunologica Scandinavica. 2015; 123(7):596-603

11. Hans CP, Weisenburger DD, Greiner TC, Gascoyne RD, Delabie J, Ott G, Muller-Hermelink HK, Campo E, Braziel RM, Jaffe ES, et al. Confirmation of the molecular classification of diffuse large B-cell lymphoma by immunohistochemistry using a tissue microarray. Blood. 2004;103(1):275-82.

12. Paik JH, Nam SJ, Kim TM, Heo DS, Kim CW, Jeon YK. Overexpression of sphingosine-1-phosphate receptor 1 and phospho-signal transducer and activator of transcription 3 is associated with poor prognosis in rituximabtreated diffuse large B-cell lymphomas. BMC cancer. 2014:14:911.

13. Mahmoud AZ, George TI, Czuchlewski DR, Zhang QY, Wilson CS, Sever CE, Bakhirev AG, Zhang D, Steidler NL, Reichard KK, et al. Scoring of MYC protein expression in diffuse large B-cell lymphomas: concordance rate among hematopathologists. Modern pathology : an official journal of the United States and Canadian Academy of Pathology, Inc. 2015;28(4):545-51.

14. Yoon SO, Jeon YK, Paik JH, Kim WY, Kim YA, Kim JE, Kim CW. MYC translocation and an increased copy number predict poor prognosis in adult diffuse large B-cell lymphoma (DLBCL), especially in germinal centrelike B cell (GCB) type. Histopathology. 2008;53(2):205-17.

15. Green TM, Young KH, Visco C, Xu-Monette ZY, Orazi A, Go RS, Nielsen O, Gadeberg OV, Mourits-Andersen T, Frederiksen M, et al. Immunohistochemical double-hit score is a strong predictor of outcome in patients with diffuse large B-cell lymphoma treated with rituximab plus cyclophosphamide, doxorubicin, vincristine, and prednisone. Journal of clinical oncology : official journal of the American Society of Clinical Oncology. 2012;30(28):3460-7.

16. Levy O, Deangelis LM, Filippa DA, Panageas KS, Abrey LE. BCI-6 predicts improved prognosis in primary central nervous system lymphoma. Cancer. 2008;112(1):151-6.

17. Tapia G, Baptista MJ, Munoz-Marmol AM, Gaafar A, Puente-Pomposo M, Garcia O, Marginet-Flinch R, Sanz C, Navarro JT, Sancho JM, et al. MYC protein expression is associated with poor prognosis in primary diffuse large B-cell lymphoma of the central nervous system. Apmis. 2015;123(7): 596-603.

18. Lin CH, Kuo KT, Chuang SS, Kuo SH, Chang JH, Chang KC, Hsu HC, Tien HF, Cheng AL. Comparison of the expression and prognostic significance of differentiation markers between diffuse large B-cell lymphoma of central nervous system origin and peripheral nodal origin. Clinical cancer research : an official journal of the American Association for Cancer Research. 2006:12(4):1152-6.

19. Camilleri-Broet S, Criniere E, Broet P, Delwail V, Mokhtari K, Moreau A, Kujas M, Raphael M, Iraqi W, Sautes-Fridman C, et al. A uniform activated B-cell-like immunophenotype might explain the poor prognosis of primary central nervous system lymphomas: analysis of 83 cases. Blood. 2006;107(1):190-6.

20. Lossos C, Bayraktar S, Weinzierl E, Younes SF, Hosein PJ, Tibshirani RJ, Sutton Posthumus J, DeAngelis LM, Raizer J, Schiff D, et al. LMO2 and BCL6 are associated with improved survival in primary central nervous system lymphoma. British journal of haematology. 2014;165(5):640-8.

21. Braaten KM, Betensky RA, de Leval L, Okada Y, Hochberg FH, Louis DN, Harris NL, Batchelor TT. BCL-6 expression predicts improved survival in patients with primary central nervous system lymphoma. Clinical cancer research : an official journal of the American Association for Cancer Research. 2003;9(3):1063-9.

22. Kreher S, Johrens K, Strehlow F, Martus P, Borowiec K, Radke J, Heppner F, Roth $\mathrm{P}$, Thiel $\mathrm{E}$, Pietsch T, et al. Prognostic impact of B-cell lymphoma 6 in primary CNS lymphoma. Neuro-oncology. 2015;17(7):1016-21.

23. Rubenstein JL, Hsi ED, Johnson JL, Jung SH, Nakashima MO, Grant B, Cheson BD, Kaplan LD. Intensive chemotherapy and immunotherapy in patients with newly diagnosed primary CNS lymphoma: CALGB 50202 (Alliance 50202). Journal of clinical oncology : official journal of the American Society of Clinical Oncology. 2013;31(25):3061-8.
24. Momota H, Narita Y, Maeshima AM, Miyakita Y, Shinomiya A, Maruyama T, Muragaki Y, Shibui S. Prognostic value of immunohistochemical profile and response to high-dose methotrexate therapy in primary CNS lymphoma. Journal of neuro-oncology. 2010;98(3):341-8.

25. Chang CC, Kampalath B, Schultz C, Bunyi-Teopengco E, Logan B, Eshoa C, Dincer AP, Perkins SL. Expression of p53, C-Myc, or BCl-6 suggests a poor prognosis in primary central nervous system diffuse large B-cell lymphoma among immunocompetent individuals. Archives of pathology \& laboratory medicine. 2003;127(2):208-12.

26. Raoux D, Duband S, Forest F, Trombert B, Chambonniere ML, Dumollard JM, Khaddage A, Gentil-Perret A, Peoc'h M. Primary central nervous system lymphoma: immunohistochemical profile and prognostic significance. Neuropathology : official journal of the Japanese Society of Neuropathology. 2010;30(3):232-40.

27. Hattab EM, Martin SE, Al-Khatib SM, Kupsky WJ, Vance GH, Stohler RA, Czader M, Al-Abbadi MA. Most primary central nervous system diffuse large B-cell lymphomas occurring in immunocompetent individuals belong to the nongerminal center subtype: a retrospective analysis of 31 cases. Modern pathology : an official journal of the United States and Canadian Academy of Pathology, Inc. 2010;23(2):235-43.

\section{Submit your next manuscript to BioMed Central and we will help you at every step:}

- We accept pre-submission inquiries

- Our selector tool helps you to find the most relevant journal

- We provide round the clock customer support

- Convenient online submission

- Thorough peer review

- Inclusion in PubMed and all major indexing services

- Maximum visibility for your research

Submit your manuscript at www.biomedcentral.com/submit
( ) BioMed Central 